\title{
Desempenho térmico e absortância solar de telhas de fibrocimento sem amianto submetidas a diferentes processos de envelhecimento natural
}

\author{
Thermal performance and solar absorptance of asbestos- \\ free fiber cement roof tiles under different natural aging \\ processes
}

\section{Thamys da Conceição Costa Coelho Carlos Eduardo Marmorato Gomes Kelen Almeida Dornelles}

\section{Resumo}

A

s telhas de fibrocimento, ao longo de sua vida útil, passam por três processos de envelhecimento natural que podem alterar a absortância solar de sua superfície e o seu desempenho térmico: a carbonatação, a eflorescência e o desenvolvimento de fungos. Com o objetivo de identificar o impacto desses processos sobre sua absortância e seu desempenho térmico, esta pesquisa incluiu três etapas: a) determinação dos processos de envelhecimento natural em telhas com idades de 28 dias e após 36 meses de exposição; b) medição de temperaturas superficiais por termografia; e c) ensaios de refletância com espectrofotômetro para cálculo da absortância solar. Os resultados indicaram que, após 36 meses de envelhecimento natural, a carbonatação reduziu as absortâncias e as temperaturas superficiais das telhas quando comparadas com as telhas novas de 28 dias. Entretanto, as telhas com fungos após 36 meses apresentaram aumento nas absortâncias e temperaturas superficiais, indicando que a presença de fungos pode incrementar os ganhos de calor solar pelas edificações. Os resultados comprovam que os processos de envelhecimento natural de telhas de fibrocimento alteram consideravelmente seu desempenho térmico ao longo da vida útil de uma edificação.

Palavras-chaves: Telhas. Carbonatação. Eflorescência. Absortância solar. Desempenho térmico. Envelhecimento natural.

Thamys da Conceição Costa

Coelho Universidade Estadual de Campinas Campinas - SP - Brasil

Carlos Eduardo Marmorato Gomes Universidade Estadual de Campinas Campinas - SP - Brasil

Kelen Almeida Dornelles Universidade de São Paulo São Carlos - SP - Brasil

Recebido em 25/03/16 Aceito em 29/07/16

\section{Abstract}

Fiber cement roof tiles undergo natural aging processes that may change their surface solar absorptance and thermal performance: carbonation, efflorescence and fungal development. With the aim of identifying the impact of these processes on their absorptance and thermal performance, this research study was undertaken in three stages: a) determination of the aging processes in tiles naturally aged for 28 days and after 36 months of exposure; b) surface temperature measurements by infrared thermography; and c) spectral reflectance measurements with a spectrophotometer to calculate the solar absorptance of the tiles. The results indicate that the carbonation process after 36 months of natural aging reduced the tiles' absorptance and surface temperatures when compared to the new 28 days' tiles. However, tiles with fungal growth after 36 months of exposure showed increased initial absorptance and surface temperatures, indicating that fungal growth can increase building solar heat gains. The results indicated that the natural aging processes of fiber cement tiles considerably affect its thermal performance over the building's lifetime.

Keywords: Tiles. Carbonation. Leaching. Solar absorptance. Thermal performance. Natural aging. 


\section{Introdução}

As telhas onduladas de fibrocimento são elementos construtivos de baixo custo e, por isso, possuem importante papel na construção de habitações sociais no Brasil. Esse tipo de habitação é caracterizado, principalmente, pela autoconstrução, a qual apresenta a participação do usuário na construção da moradia (KALIL, 2004). Em análise de dez habitações populares na cidade de São Paulo, Balthazar (2012) constatou que a adoção dos materiais baseia-se no custo e que, nas coberturas, predomina o uso de telhas onduladas de fibrocimento. Devido à acessibilidade econômica, é o primeiro produto para coberturas consumido por esse segmento, depois da lona preta, o que contribui para a redução do déficit habitacional (ETERNIT, 2012).

O fibrocimento é um material compósito que utiliza como ligante o cimento Portland. Até o ano de 2007, a principal fibra usada na fabricação de telhas era o amianto, que tem origem mineral. Todavia, proibiu-se no Brasil (inicialmente com a Lei n. 9.055/1995 (BRASIL, 1995)) o emprego do amianto na fabricação de quaisquer componentes construtivos. A substituição do amianto pela tecnologia das fibras sintéticas possui normatização recente no Brasil - NBR 15210-1 (ABNT, 2005) - "cimento reforçado com fios sintéticos". Algumas entidades consideram essa aplicação sustentável, devido à possibilidade de se reciclar produtos derivados do plástico (polipropileno) e utilizá-los na fabricação de produtos de fibrocimento (ASSOCIAÇÃO..., 2014).

Como qualquer material de construção, as telhas sofrem deterioração devido à exposição aos agentes ambientais como chuvas, poluição e radiação solar. No caso específico das telhas de fibrocimento, os principais processos naturais de deterioração ao longo de sua vida útil são a carbonatação, a eflorescência e o desenvolvimento de fungos, os quais ocorrem devido à exposição às intempéries e à periodicidade da manutenção da estrutura em serviço.

A carbonatação é um processo físico e químico natural, que ocorre nos materiais de base cimentícia expostos a concentrações de dióxido de carbono $\left(\mathrm{CO}_{2}\right)$ da atmosfera a qual estão expostos. A reação entre os materiais de base cimentícia e o $\mathrm{CO}_{2}$ libera da estrutura do material principalmente o carbonato de cálcio $\left(\mathrm{CaCO}_{3}\right)$, formando, nas telhas de fibrocimento, camadas periféricas que alteram o seu aspecto natural, entre eles sua coloração, podendo também reduzir a porosidade do material e reforçar a sua superfície (GLASSER;
MARCHAND; SAMSON, 2008; TASCA, 2012; ALMEIDA et al., 2010). A fixação do hidróxido de cálcio na superfície proporciona lareamento desses elementos, o que pode alterar a absortância solar da telha de fibrocimento que sofreu esse processo. Verifica-se, então, um fenômeno particular dos materiais de base cimentícia, o que não pode ser relacionado às telhas cerâmicas ou a outros tipos de materiais

A eflorescência, por outro lado, é resultante da penetração de líquidos nos poros dos materiais à base de cimento, diluindo sais que migram para o meio externo. Apesar de também clarear a superfície, a eflorescência causa uma aparência esteticamente indesejável nas telhas, de dimensões irregulares e coloração que varia de acordo com a orientação da edificação (DOW; GLASSER, 2003), além do aumento da porosidade e permeabilidade e perda de resistência mecânica do material (GLASSER; MARCHAND; SAMSON, 2008). Por esse motivo, a eflorescência é evitada em telhas de concreto, especialmente coloridas, por meio do uso de aditivos impermeabilizantes ou hidrofugantes, bem como uso de adições que alteram as características da matriz cimentícia.

Dias et al. (2008) analisaram amostras de telhas onduladas de fibrocimento expostas às intempéries das cidades de São Paulo, SP, por 37 anos e de Criciúma, SC, por 30 anos. Em ambas as situações as telhas apresentaram significativa carbonatação, porém as amostras de Criciúma apresentavam também lixiviação.

Em condições normais de exposição, com concentrações de $0,03 \%$ a $0,1 \%$ de $\mathrm{CO}_{2}$, a carbonatação pode ocorrer ao longo de vários anos (PAULETTI; POSSAN; DAL MOLIN, 2007). No fibrocimento, esse fenômeno pode ser observado em até dois anos (DOGGETT, 2014). Embora seja possível estabelecer uma relação entre a intensidade da carbonatação com o tempo, a maioria dos estudos laboratoriais não é consensual e apresenta difícil correlação às condições naturais de exposição (PAULETTI; POSSAN; DAL MOLIN, 2007).

Já o desenvolvimento de fungos e outros agentes biológicos, apesar de não promover a degradação física das telhas de fibrocimento, origina camadas escuras que modificam a coloração inicial da superfície. Essas alterações são resultado, principalmente, da localização da edificação e dos diversos agregados associados ao cimento Portland, como mostra o estudo de Tanaca et al. (2011), o qual mostrou que os exemplares pesquisados advindos de cidades com menor

148 Coelho, T. da C. C.; Gomes, C. E. M.; Dornelles, K. A. 
amplitude térmica e temperaturas do ar e umidade relativa médias apresentaram menor concentração de fungos. Assim como no processo de carbonatação, a poluição dos grandes centros urbanos também tem um papel relevante na manifestação biológica em compostos de fibrocimento, uma vez que as partículas em suspensão no ar, oriundas da queima de combustíveis fósseis, nutrem os fungos e facilitam a sua proliferação (TANACA et al., 2011).

Um impacto importante dos processos de envelhecimento das telhas de fibrocimento, assim como de outros tipos de telhas expostas aos agentes atmosféricos naturais, é a alteração da sua absortância solar, propriedade definida como a razão entre a energia solar absorvida por uma superfície e a energia total incidente sobre ela (ABNT, 2005). Portanto, quanto maior a absortância solar das telhas, maior será a absorção de radiação solar e consequentemente o aumento de suas temperaturas superficiais, assim como o impacto sobre o desempenho térmico das edificações. A absortância, portanto, influencia os ganhos de calor solar e o fluxo de calor por meio do envelope da edificação (SANTOS, 2013). Como esclarece Dornelles (2008), apesar de não ser o único fator a impactar a carga térmica das edificações, a absortância tem efeito significativo, principalmente em edificações leves.

A radiação solar é um dos mais importantes contribuintes para o ganho térmico em edifícios em países de clima quente. Portanto, reduzir sua absorção pelo envelope construtivo das edificações, principalmente das coberturas em habitações térreas ou de poucos pavimentos, irá afetar significativamente o desempenho térmico e por consequência o consumo energético dos edifícios (TAHA et al., 1988). Dados do Balanço Energético Nacional de 2015 (EMPRESA..., 2015) indicam que as edificações são responsáveis por $50 \%$ de toda a energia elétrica utilizada no Brasil. Tanto em edifícios residenciais (25\%) como comerciais $(17 \%)$ e públicos $(8 \%)$, esse consumo pode ser explicado pela necessidade de sistemas de climatização que facilitam o desenvolvimento das atividades humanas dentro dos espaços construídos. Assim, o desempenho térmico do envelope construtivo irá influenciar significativamente na eficiência energética dos edifícios.

Diversas pesquisas verificaram a economia de energia para condicionamento artificial pela alteração da absortância solar da cobertura de edificações (AKBARI et al., 2005; BOZONNET; DOYA; ALLARD, 2011; BRITO FILHO; HENRIQUEZ; DUTRA, 2011; LEVINSON; AKBARI; REILLY, 2007; KOLOKOTRONI;
GOWREESUNKER; GIRIDHARAN, 2013; ROMEO; ZINZI, 2013; SYNNEFA; SANTAMOURIS, 2012). No entanto, esse desempenho pode ser modificado ao longo do tempo, caso não se considerem os impactos na alteração da absortância após o período de exposição às intempéries, resultado do envelhecimento natural dos materiais de cobertura (SLEIMAN et al., 2011).

Estudos já comprovaram que a exposição dos revestimentos de coberturas aos agentes atmosféricos altera as características iniciais de absorção dos materiais, além da modificação de cor, perda de brilho, empolamento, entre outras propriedades dessas superfícies (BERDAHL et al., 2008; BRETZ; AKBARI, 1997; DORNELLES; SICHIERI, 2014; LEVINSON; BERDAHL; AKBARI, 2005; PAOLINI et al., 2014; WERLE; LOH; JOHN, 2014). De maneira geral, a exposição ao tempo tende a aumentar a absortância de materiais claros e diminuir a absortância de materiais escuros. Em estudo realizado por Bretz e Akbari (1997), avaliou-se os efeitos provocados pelo envelhecimento de 26 tipos de telhados que originalmente apresentavam baixas absortâncias. Os autores concluíram que esses efeitos dependem do tipo de revestimento, de sua textura, da inclinação da cobertura e da proximidade de fontes de sujeira. O maior aumento da absortância, em torno de $20 \%$, ocorre no primeiro ano. Após o segundo ano, os acréscimos são pouco significativos, reduzindo entre $10 \%$ e $20 \%$ a economia originalmente estimada de energia pelo uso da baixa absortância. Os autores também destacam que a lavagem periódica das superfícies de coberturas pode restabelecer entre 90 e $100 \%$ da absortância original.

Em outro estudo, Akbari et al. (2005) comparam os efeitos do envelhecimento natural em dezenas de coberturas de baixa absortância, sob diferentes condições de conservação e limpeza. Os resultados comprovaram que, com o passar do tempo, as absortâncias são progressivamente afetadas pela radiação ultravioleta e por acúmulo de pó, sujeira e poluição urbana. No interior das cidades, a tendência do envelhecimento é aumentar as baixas absortâncias, pois o pó e outros detritos urbanos acumulados sobre as superfícies geralmente apresentam absortâncias médias. Esses resultados também foram comprovados por Sleiman et al. (2011), que avaliaram diferentes revestimentos para cobertura expostos em três cidades com condições climáticas distintas nos Estados Unidos (Arizona, Flórida e Ohio).

Dados de refletância solar de telhas novas de fibrocimento produzidas no Brasil foram publicados por alguns autores (PRADO; 
FERREIRA, 2005; UEMOTO; SATO; JOHN, 2010; WERLE; LOH; JOHN, 2014), com valores de $39,5 \%, 47,3 \%$ e $50 \%$ (absortância solar de $60,5 \%, 52,7 \%$ e $50 \%$ respectivamente). Esses valores são fundamentais para a avaliação do desempenho térmico de habitações, seja por meio de critérios e requisitos para os sistemas de coberturas apresentados em normas e certificações, como a NBR 15575 (ABNT, 2013) ou o RTQ do Procel Edifica (INSTITUTO..., 2010), ou ainda como dado de entrada em programas de simulação computacional do desempenho termoenergético de edificações.

No entanto, não há dados disponíveis no Brasil sobre alterações da absortância solar de telhas de fibrocimento submetidas a diferentes processos de envelhecimento natural ao longo de sua vida útil, assim como do impacto sobre as temperaturas superficiais delas quando expostas ao sol. Nesse contexto, este artigo apresenta resultados de uma pesquisa experimental em que foram avaliados os efeitos dos processos naturais de envelhecimento de telhas de fibrocimento sem amianto sobre suas características superficiais e os impactos na absortância solar e no desempenho térmico delas após esses processos. Pretende-se, com este estudo, apresentar contribuições sobre o uso adequado de telhas de fibrocimento de acordo com seu comportamento térmico frente aos processos de envelhecimento natural desses revestimentos. Considerando que as telhas de fibrocimento são amplamente utilizadas no mercado da habitação no Brasil, também se pretende contribuir para o conhecimento disponível acerca das propriedades térmicas de compósitos de cimento nesse contexto, e sobre os processos que intervenham no desempenho térmico desses componentes.

\section{Método}

A pesquisa foi dividida em três etapas, a fim de se obter os dados necessários à correlação dos impactos do envelhecimento natural de telhas de fibrocimento sobre a absortância solar e suas temperaturas superficiais:

(a) determinação dos processos de envelhecimento natural em telhas com idades de 28 dias e após 36 meses de exposição;

(b) medição de temperaturas superficiais por termografia; e

(c) ensaios de refletância com espectrofotômetro para cálculo da absortância solar.

Para as análises, foram selecionadas amostras de telhas de fibrocimento sem amianto: uma telha nova com 28 dias e duas com 36 meses em operação, oriundas do mesmo fabricante. Apesar de a telha de 28 dias não ser do mesmo lote das demais, seu processo de produção obedeceu aos mesmos critérios, composição de materiais e tipo das demais amostras com 36 meses, o que permite a comparação para efeitos deste estudo relativo às alterações da absortância solar. Todas as telhas em análise apresentaram espessura nominal de $5 \mathrm{~mm}$.

As telhas ficaram expostas no campus da Universidade Estadual de Campinas (Unicamp), instaladas na cobertura do edifício do Laboratório de Materiais de Construção (LMC) da FEC, na cidade de Campinas, estado de São Paulo, região Sudeste do Brasil. A cidade está inserida em um clima tropical de altitude, caracterizado por baixo índice pluviométrico e grande amplitude térmica (CENTRO..., 2015). Nessa cidade, predomina o calor sobre o frio durante o ano. No inverno, a diferença entre as temperaturas do dia e da noite pode chegar a até $13^{\circ} \mathrm{C}$ (CHVATAL; LABAKI; KOWALTOWSKI, 2000).

A cidade está localizada a $22^{\circ} 48^{\prime} 56^{\prime \prime}$ latitude sul e a $47^{\circ} 03^{\prime} 28^{\prime \prime}$ longitude oeste, $640 \mathrm{~m}$ acima do nível do mar. No período de 1988 a 2008, a média anual de temperatura foi de $22^{\circ} \mathrm{C}$, e no período mais quente (entre os meses de novembro e março), que coincide com a transição entre as estações de primavera e verão, a média da temperatura do ar foi de $24,7^{\circ} \mathrm{C}$ (CENTRO..., 2015). Apesar de o registro de precipitação pluviométrico ter se mostrado elevado no registro feito para esse período, uma característica da cidade de Campinas mitiga a elevação da umidade relativa do ar, que é a elevada velocidade dos ventos na região.

\section{Determinação dos processos de envelhecimento}

O método para determinação de processos de envelhecimento em compósitos de cimento é a aplicação de solução de fenolftaleína, devido a vantagens como o baixo custo e a facilidade de execução (TASCA, 2012). A fenolftaleína é um componente orgânico, inodoro e incolor em meio básico, mas que em contato com substâncias ácidas adquire uma coloração rosada. A utilização dessa substância na determinação da profundidade do ataque de $\mathrm{CO}_{2}$ nos materiais de base cimentícia é feita indiretamente, pois a cor que a amostra adquire representa onde o $\mathrm{pH}$ do material é superior a 9 (GLASSER; MARCHAND; SAMSON, 2008).

$\mathrm{O}$ procedimento para determinação da profundidade da carbonatação, com uso de fenolftaleína, é descrito pela União Internacional de Laboratórios e Pesquisadores em Materiais de Construção, Sistemas e Estruturas em RILEM Technical Recommendations (1988) como 
aplicável tanto para ensaios em laboratório quanto para utilização em campo.

Apesar de não ser o objetivo desta pesquisa determinar a profundidade da carbonatação nas telhas analisadas, esse procedimento permite identificar a ocorrência do fenômeno, que é o objetivo desta etapa do trabalho. A aferição da carbonatação foi realizada de forma visual e a diferença entre a porção carbonatada e não carbonatada do material foi realizada com uma régua graduada em milímetros. Os ensaios foram realizados no Laboratório de Materiais de Construção (LMC) da Faculdade de Engenharia Civil, Arquitetura e Urbanismo da Unicamp.

Para a determinação do processo de carbonatação nas telhas, o procedimento seguiu as seguintes etapas:

(a) extração dos corpos de prova de $5 \mathrm{~cm} \mathrm{x} 5 \mathrm{~cm}$ oriundos das telhas de 28 dias e 36 meses em operação, objetos deste estudo;

(b) aplicação de solução de $1 \%$ de fenolftaleína em $70 \%$ de álcool etílico, em laboratório; e

(c) registro da ocorrência de manchas avermelhadas, correspondentes à reação entre a solução de fenolftaleína e o pH ácido característico das regiões não carbonatadas dos compósitos de cimento.

Para a verificação da presença de eflorescência e fungos, foi realizada identificação visual na superfície de amostras de $5 \mathrm{~cm}$ x $5 \mathrm{~cm}$ retiradas dos espécimes com 36 meses em operação, de forma comparativa.

\section{Medição de temperaturas superficiais por termografia de infravermelho}

Para a análise das temperaturas superficiais das telhas de fibrocimento submetidas a diferentes processos de envelhecimento natural, quando comparadas com telhas novas, foi adotado o método de medição de temperaturas superficiais por termografia de infravermelho. A termografia de infravermelho é um método de diagnóstico que tem uma ampla gama de aplicabilidade para avaliação de questões como a continuidade do isolamento e da eficiência energética da envoltória, identificação de locais de infiltração de ar e monitoramento da temperatura do ar interior (BRÁS; ROCHA; FAUSTINO, 2015; TAILEB; DEKKICHE, 2015). Também se aplica ao diagnóstico das propriedades térmicas da envoltória do edifício (FOKAIDES; KALOGIROU, 2011).
Segundo a norma BS ISO 18434 (BRITISH..., 2008), existem dois escopos em se realizar a termografia de infravermelho:

(a) comparativo; e

(b) absoluto ou sem contato.

O escopo comparativo é utilizado para fornecer informações térmicas de operação disponíveis entre componentes, enquanto a absoluta se faz necessária para conhecer a temperatura precisa do alvo da medição.

A avaliação de termografia de infravermelho comparativa qualitativa compara o padrão ou o perfil térmico do componente avaliado a um idêntico ou similar sob as mesmas condições de operação. Tem como vantagem a dispensa da necessidade de ajustes do equipamento para compensar condições atmosféricas e ambientais ou a emissividade do material do componente construtivo avaliado. Também, ao contrário do método quantitativo, afere deficiência ou diminuição na operação do componente, e não severidade (BRITISH..., 2008).

Para a obtenção das imagens de infravermelho das telhas envelhecidas naturalmente, foi adotado o seguinte procedimento.

Montou-se 3 (três) estruturas de cobertura isoladas com manta térmica metalizada, compostas de perfis metálicos conformados a frio, com espessura de $0,95 \mathrm{~mm}$, comumente empregados em construções a seco. As dimensões foram ajustadas para assentamento de duas telhas onduladas de fibrocimento, com dimensões de 0,92 $\mathrm{m}$ de largura por $2,10 \mathrm{~m}$ de comprimento, respeitada a sobreposição intercalar de meia onda (Figura 1). As estruturas foram inclinadas a $45^{\circ}$ devido à conformação da estrutura dos perfis metálicos utilizados. As telhas foram orientadas ao norte para maximizar a exposição das superfícies à incidência direta da radiação solar durante o período de medição na localidade (Campinas, SP).

As três instalações foram expostas à radiação solar direta em uma semana típica de verão, no Campus da Universidade Estadual de Campinas (Unicamp), cidade de Campinas, São Paulo. Estabeleceu-se dois dias de medição para verificação de discrepâncias entre os resultados de termografia; porém, para análise neste artigo, apenas os resultados obtidos no dia 18 de fevereiro de 2016 foram avaliados. Nesse dia, foram obtidos os dados das condições climáticas medidos pela estação meteorológica do Centro de Pesquisas Meteorológicas e Climáticas Aplicadas à Agricultura (Cepagri), localizada no campus da Unicamp. A temperatura média do ar ao longo de todo o dia foi de $26,2^{\circ} \mathrm{C}$ e a umidade relativa do ar 
média de $71,5 \%$. A variação ao longo do dia das condições ambientais é apresentada na Figura 2.

Para aferição das temperaturas de infravermelho superficiais, utilizou-se uma câmera de infravermelho da fabricante Fluke, série Ti110, com sensibilidade térmica entre $-10^{\circ} \mathrm{C}$ e $250^{\circ} \mathrm{C}$, resolução de $120 \times 160$, e faixa de temperatura para registro entre $-10^{\circ} \mathrm{C}$ e $250^{\circ} \mathrm{C}$ (Figura 3). $\mathrm{O}$ equipamento pertence ao Laboratório de Conforto Ambiental e Física Aplicada (LaCAF) da Universidade Estadual de Campinas. Para este estudo, fixou-se a distância de $4 \mathrm{~m}$ entre as estruturas e o operador da câmera, necessária para o enquadramento da estrutura ao foco deste equipamento.
Analisou-se as imagens de infravermelho no software SmartView 3.12, da fabricante da câmera, para cada uma das telhas. A partir dos relatórios de medição, fornecidos pelo software de leitura das termografias, foi possível comparar os resultados da distribuição de temperatura superficial em uma área de interesse da imagem de infravermelho das três estruturas analisadas, chamada "caixa central". A "caixa central" é um conjunto de marcadores que formam um polígono, utilizado pelo software para facilitar a leitura e interpretação de dados de temperatura superficial, excluindo da análise dos resultados possíveis irregularidades, temperaturas de outros objetos e do entorno.

\section{Figura 1 - Estruturas de coberturas montadas para medição de temperaturas superficiais em campo}
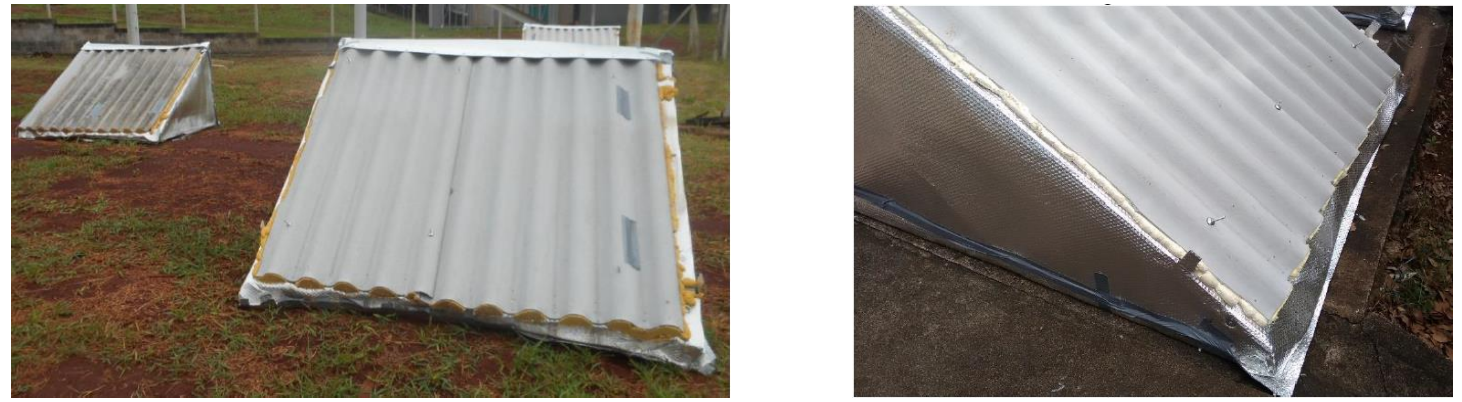

Figura 2 - Variação da temperatura e umidade relativa do ar ao longo do dia de medições das temperaturas das telhas

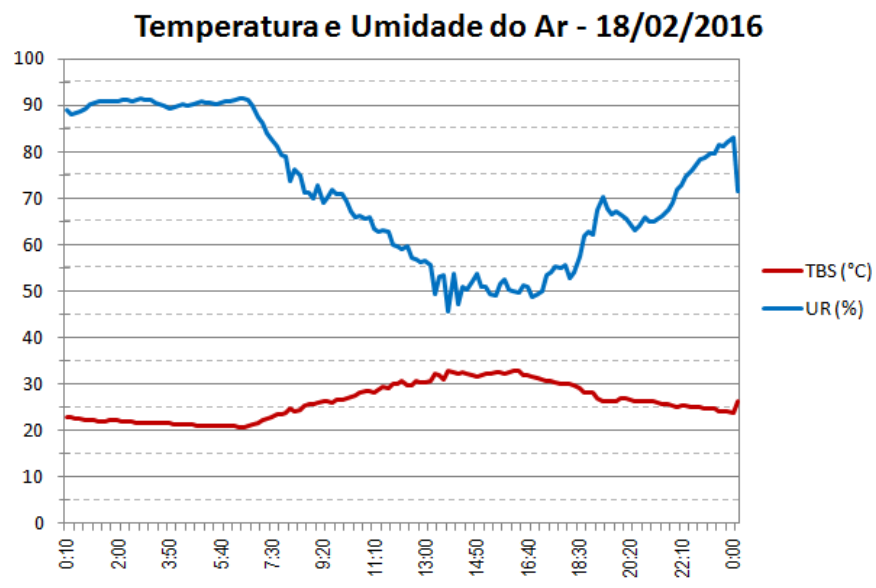

152 Coelho, T. da C. C.; Gomes, C. E. M.; Dornelles, K. A. 
Figura 3 - Câmera de IV da Fluke, utilizada na pesquisa

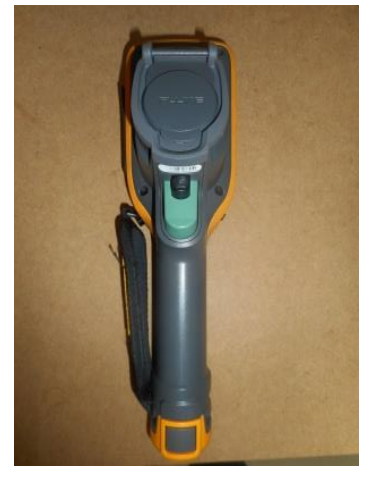

\section{Ensaios de refletância solar}

A norma ASTM E903-12 (AMERICAN..., 2012b) apresenta um método com uso de espectrofotômetro, equipado com esfera integradora, para medição da refletância difusa e posterior cálculo dos valores de absortância. A escala de medição recomendada pela ASTM E90312 vai de $300 \mathrm{~nm}$ a $2.500 \mathrm{~nm}$. Porém, para que seja aplicado, é necessário ter a distribuição de um espectro solar de referência, nesse caso adotado o da ASTM G173-12 (AMERICAN..., 2012a) conforme recomendação da própria norma ASTM E903-12 (AMERICAN..., 2012b). O método de cálculo para o ajuste dos valores de refletância medidos com espectrofotômetro e a distribuição do espectro solar de referência é detalhado em Dornelles (2008).

O espectrofotômetro é o equipamento mais preciso utilizado para se obter a refletância de uma superfície ao longo de todo o espectro solar (DORNELLES, 2008) e, a partir dessa variável térmica, calcular-se outras, tal como a absortância solar dos materiais.

Nesta pesquisa, a obtenção das absortâncias adotou o seguinte procedimento:

(a) obtenção das refletâncias espectrais ( $\rho$ ) por meio do espectrofotômetro da fabricante Varian, modelo Cary 5G, para cada amostra avaliada:

- telha nova (28 dias): 3 amostras (N1; N2 e N3);

- telha carbonatada (36 meses): 3 amostras $(\mathrm{C} 1 ; \mathrm{C} 2$ e C3);

- telha carbonatada e com eflorescência (36 meses): 3 amostras (C4; C5 e C6); e

- telha com fungos (36 meses): 3 amostras (F1; F2 e F3).

(b) cálculo das refletâncias médias $(\rho)$ por faixa do espectro solar (300 $\mathrm{nm}$ a $2.500 \mathrm{~nm})$ correspondente às regiões do ultravioleta (UV),

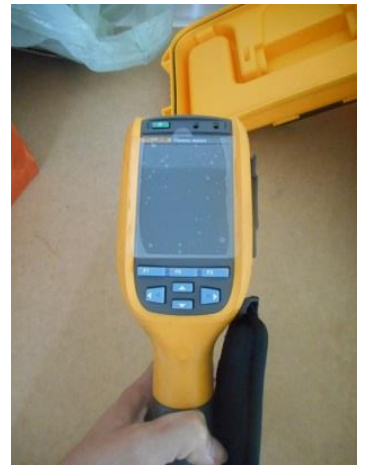

visível (VIS), infravermelho (IV) e espectro solar total (total);

(c) ajuste dos valores de refletância $(\rho)$ ao espectro solar padrão de referência (padrão), recomendado pela ASTM E903-12

(AMERICAN..., 2012). Ex.: Amostra de telha nova $\mathrm{N} 1 \times$ espectro solar de referência $($ SolPadr $)=$ refletância ajustada ( $\left.\rho_{\text {Ajustada }}\right)$;

(d) média total das refletâncias ajustadas $\left(\rho_{\text {Ajustada }}\right)$ na faixa do espectro solar correspondente à radiação ultravioleta (UV); visível (VIS); infravermelho (IV); e total;

(e) cálculo da refletância total ajustada $\left(\rho_{\text {totalAjustada }}\right)$ : produto da média total das refletâncias ajustadas, pela média total das refletâncias, por faixa do espectro. Ex: $\left(\rho_{\text {totalAjustada }}\right)$ $=$ média aritmética $\rho_{\text {Ajustada }} /$ média aritmética de $\rho$;

(f) obtenção da absortância solar $\left(\alpha_{\text {medida }}\right)$ : utilizando-se como parâmetro $\rho$, sem ajuste ao espectro solar padrão;

(g) obtenção da absortância solar total ajustada $\left(\alpha_{\text {Ajust Média }}\right)$ : média dos valores de $\rho_{\text {Ajustada }}$ por amostra de telha segundo a equação da termodinâmica: $\alpha_{\text {medida }}=100 \%-\rho$ e $\alpha_{\text {Ajust média }}=$ $100 \%$ - $\rho_{\text {Ajustada }} ; \mathrm{e}$

(h) apresentação dos gráficos de absortância espectral para discussão dos resultados.

\section{Resultados}

A primeira etapa da pesquisa compreendeu a determinação dos processos de envelhecimento das telhas, por meio da aplicação da fenolftaleína. Na telha nova de 28 dias em operação, pode-se observar que toda a espessura da amostra reagiu com o composto químico, apresentando a coloração avermelhada e indicando que o material ainda não passou pelo processo de carbonatação (Figura 4), conforme indica o procedimento apresentado na RILEM Technical Recommendations (1988). 
Figura 4 - Telha de fibrocimento de 28 dias de idade

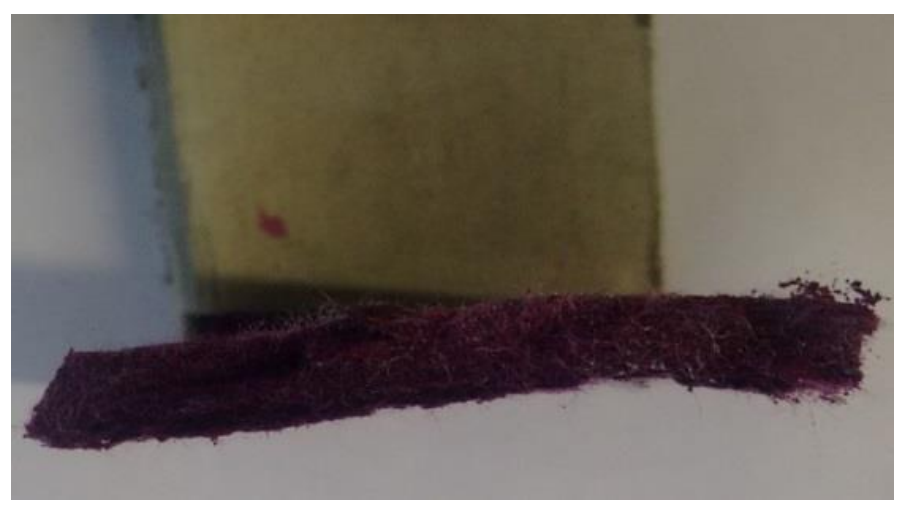

Comparativamente, são apresentados na Figura 5 os resultados obtidos para as telhas com 36 meses em operação, carbonatadas e com fungos. Observa-se que a região não carbonatada corresponde a uma pequena parcela do interior da telha.

Visualmente, pode-se observar que as amostras de telhas de fibrocimento com fungos apresentaram placas escurecidas. De acordo com Shirakawa et al. (2014), fungos e bactérias fototróficos se desenvolvem sobre telhas para obter energia para a realização de reações químicas para alimentação. A poluição é um importante facilitador da contaminação por fungos superficiais, porque fornece nutrientes ao desenvolvimento fototrófico.

Uma vez identificados os processos de envelhecimento por meio das amostras de telhas, a análise da temperatura superficial por termografia realizada nas três estruturas tem seus resultados ilustrados a seguir.

O levantamento de campo da distribuição de energia térmica radiante foi realizado nas telhas envelhecidas naturalmente de 28 dias e 36 meses, as quais foram expostas ao sol no período entre 6h30min e 20h30min do dia 18 de fevereiro de 2016, com registros das imagens térmicas a cada 2 horas. As imagens termográficas apresentadas na Figura 6 foram obtidas por medições de temperatura superficial às $12 \mathrm{~h} 30 \mathrm{~min}$, horário com alta incidência de radiação solar no dia da medição, sendo aquele que resultou em maiores temperaturas ao longo de todo o dia.

Como ilustrado na Figura 6, visualmente e comparativamente à telha nova de 28 dias, aquela de 36 meses com fungos escureceu, enquanto aquela comprovadamente carbonatada e com eflorescência aparentou clareamento superficial. Como a percepção visual humana detecta apenas um pequeno intervalo de comprimentos de onda da radiação solar, não é possível identificar a absortância ou refletância solar de uma superfície em relação ao espectro total apenas visualmente (DORNELLES, 2008). Todavia, é sabido que quanto mais próximo da cor branca menor a disposição da superfície à absorção de calor solar.

No termograma das telhas com fungos, foi possível notar a natureza irregular da expressão fúngica na distribuição da temperatura da superfície. Na crista das ondulações da telha (parte alta da ondulação), o depósito de fungos ocorre mais intensamente, e a superfície também exibe temperaturas aparentes mais altas em comparação com outras regiões onde o fungo não se desenvolveu. A diferença de temperatura entre a crista e o vale das telhas envelhecidas há 36 meses, com fungos, chega a $6^{\circ} \mathrm{C}$.

Também se observou que as telhas carbonatadas e com eflorescência apresentaram depósitos de sais de superfície que causam manchas brancas e, na imagem térmica, aparecem com temperaturas menores. Embora a carbonatação provoque modificações como densificação da matriz e baixa na rugosidade, entre outras verificadas por Pizzol et al. (2014), esse processo de envelhecimento modificou em média $1,2^{\circ} \mathrm{C}$ a temperatura aparente média da superfície da telha carbonatada, de modo que ela se aproxima à da telha de 28 dias em operação.

Em horário de elevada taxa de radiação solar, a telha de 28 dias em operação apresentou temperatura superficial máxima de $59,7^{\circ} \mathrm{C}$; a telha de 36 meses carbonatada, $57,3^{\circ} \mathrm{C}$; enquanto aquela com presença de fungos, $61^{\circ} \mathrm{C}$. Esses resultados mostram que, comparativamente à telha nova de 28 dias, a redução da alcalinidade da matriz cimentícia da telha carbonatada e o escurecimento superficial da telha com fungos provavelmente alteram os valores de absortância solar das estruturas. Essa relação é avaliada a seguir, por meio dos resultados dos ensaios de refletância espectral e posterior cálculo da absortância solar.

154 Coelho, T. da C. C.; Gomes, C. E. M.; Dornelles, K. A. 
Figura 5 - Telha carbonatada com 36 meses em operação (esquerda) - ensaio com fenolftaleína em amostra de telha com fungos (direita)
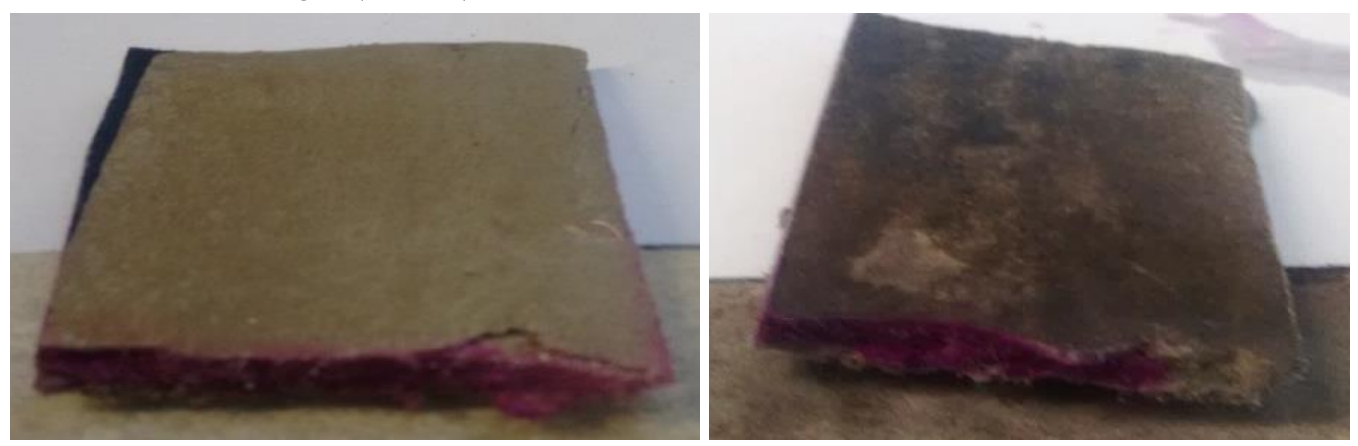

Figura 6 - Termogramas das telhas onduladas de fibrocimento sem amianto
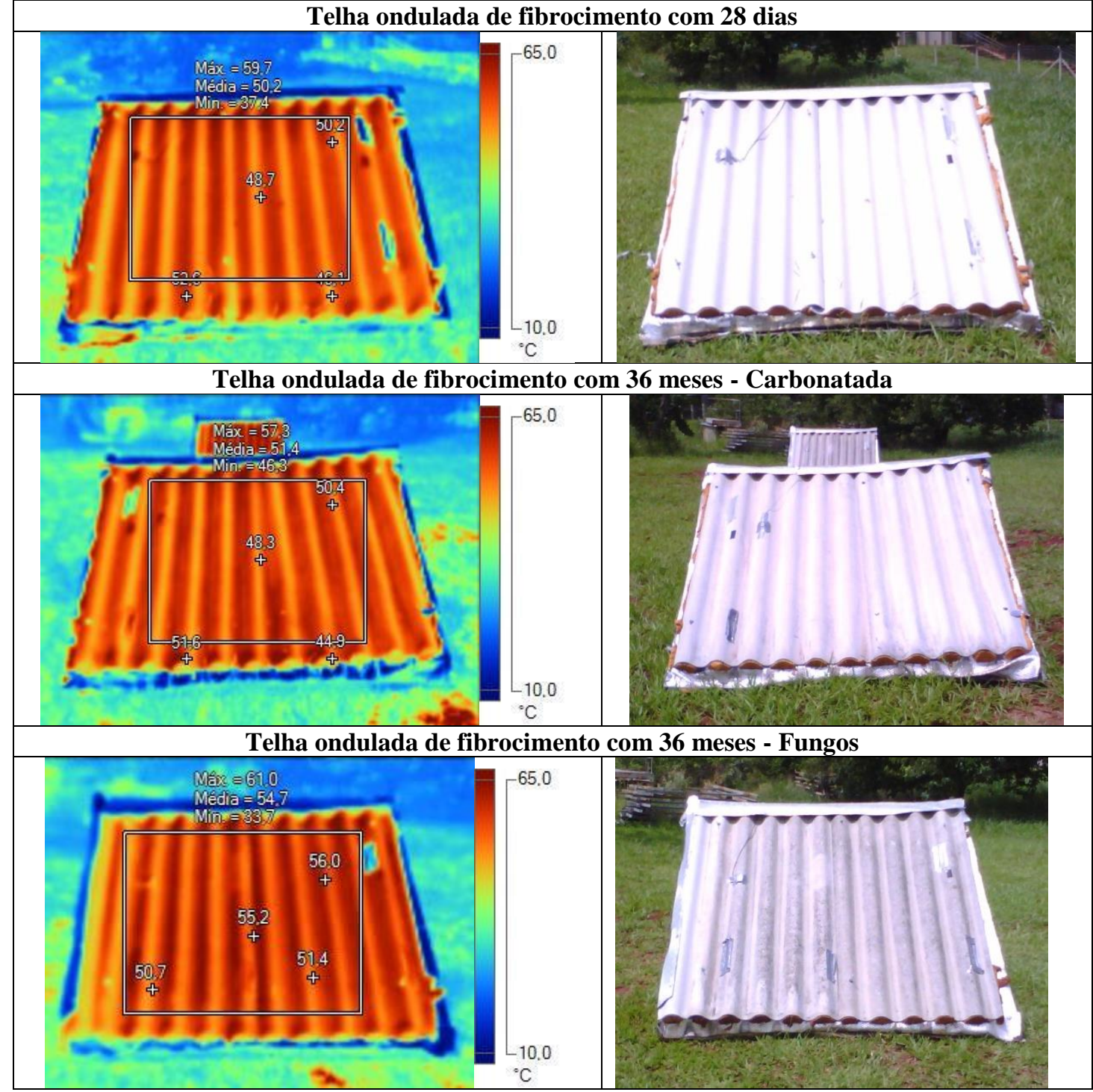
Nas Figuras 7, 8 e 9 são apresentadas as curvas espectrais de absortância medidas (em azul), e ajustadas ao espectro solar padrão (em vermelho), para as telhas nova, carbonatada e com fungos, respectivamente. Para se chegar a um valor que caracterize o comportamento térmico de cada telha, foi obtida a média aritmética simples dos resultados de absortância obtidos para cada amostra (ex: média de N1; N2 e N3), por região do espectro, a qual foi nomeada absortância média ajustada, em que:

$\alpha_{\text {medida média }}$ é a média dos valores de absortância das amostras, não ajustados ao espectro solar.

$\alpha_{\text {Ajust média }}$ é a média dos valores de absortância das amostras, ajustados ao espectro solar.

A Tabela 1 sintetiza os resultados médios de absortância solar, calculados a partir dos dados de refletância fornecidos pelo método do espectrofotômetro com esfera integradora.

As maiores diferenças entre as absortâncias das amostras desta pesquisa encontram-se na região do espectro que corresponde à luz visível. Como a principal alteração nas telhas após o envelhecimento natural é relacionado à coloração da superfície, o impacto principal sobre a absortância espectral ocorre ao longo da região do espectro visível. No entanto, ao fazer o ajuste ao espectro solar padrão, como a maior concentração de energia do espectro solar está na faixa do visível, o impacto sobre o cálculo da absortância solar é bastante significativo, conforme já evidenciado por Dornelles (2008). Esse resultado é confirmado nos valores de absortância solar obtidos para todas as telhas, conforme apresentado na Tabela 1 e na Figura 10, que apresenta as curvas de absortância espectral ajustadas para os três tipos de telhas (nova, carbonatada/com eflorescência e com fungos). A principal alteração na absortância espectral ocorre na região do espectro visível, porém também se observa diferença significativa na região do infravermelho, entre $780 \mathrm{~nm}$ e $1.400 \mathrm{~nm}$ aproximadamente. Esse mesmo comportamento também foi observado por Sleiman et al. (2011), na análise de diversos tipos de telhas expostas em três cidades com climas distintos nos Estados Unidos. A alteração da cor dos revestimentos para coberturas apresentaram impacto significativo nas absortâncias solares após 36 meses de exposição ao tempo no estudo desses autores.

As amostras carbonatadas e com eflorescência obtiveram resultados de absortância solares próximos entre si, pois a difusão do $\mathrm{CO}_{2}$ presente na atmosfera se dá de modo uniforme nos poros da matriz cimentícia, formando uma camada mais compacta e densa, como explica Pizzol et al. (2014). Como a migração de sais para o meio externo sucede o processo de desprendimento de íons de cálcio da matriz cimentícia (carbonatação), esses dois fenômenos foram considerados como um único processo no clareamento superficial das telhas onduladas de fibrocimento, e por esse motivo apenas uma curva é apresentada neste artigo, referente ao processo de carbonatação após 36 meses.

Figura 7 - Curvas espectrais de absortância da telha nova

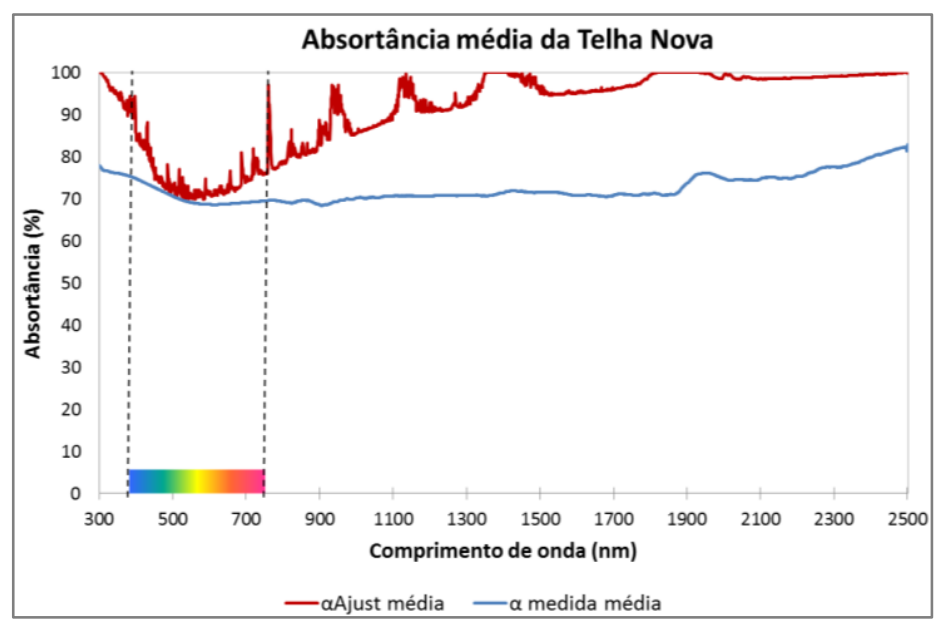

156 Coelho, T. da C. C.; Gomes, C. E. M.; Dornelles, K. A. 
Figura 8 - Curvas espectrais de absortância da telha carbonatada

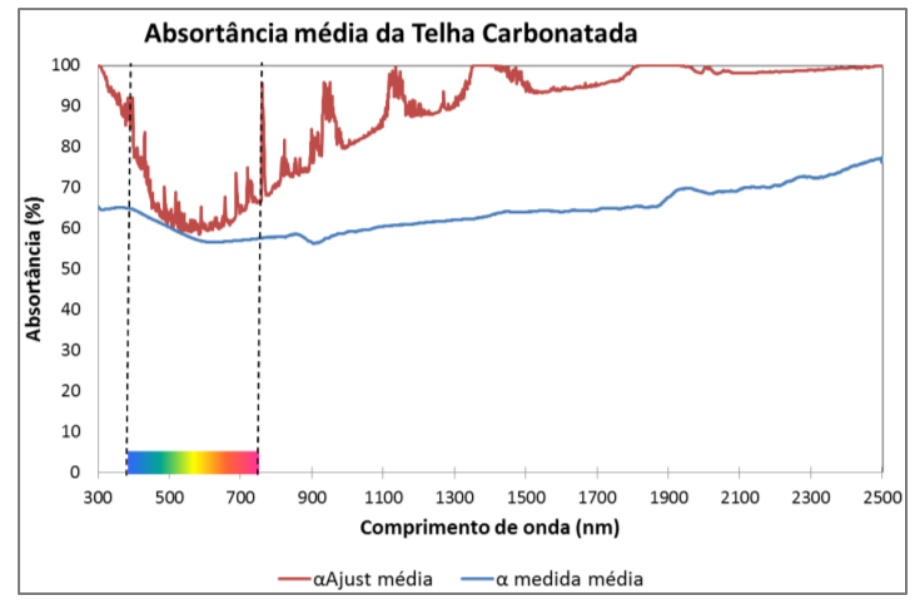

Figura 9 - Curvas espectrais de absortância da telha com fungos

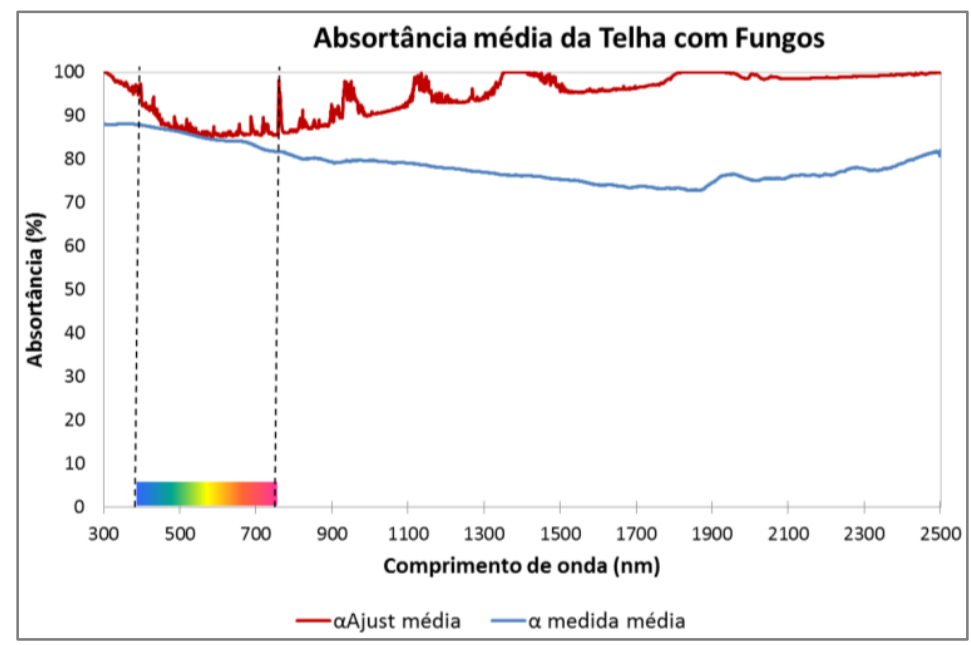

Tabela 1 - Absortâncias medidas em espectrofotômetro e ajustadas ao espectro solar padrão

\begin{tabular}{c|c|c|c|c|c|c|c|c}
\hline Faixa do espectro: & \multicolumn{2}{|c|}{ Ultravioleta } & \multicolumn{2}{c|}{ Visível } & \multicolumn{2}{c}{ Infravermelho } & \multicolumn{2}{c}{ Total (Solar) } \\
\hline & $\boldsymbol{\alpha}_{\text {medida }}$ & $\boldsymbol{\alpha}_{\text {Ajust }}$ & $\boldsymbol{\alpha}_{\text {medida }}$ & $\boldsymbol{\alpha}_{\text {Ajust }}$ & $\boldsymbol{\alpha}_{\text {medida }}$ & $\boldsymbol{\alpha}_{\text {Ajust }}$ & $\boldsymbol{\alpha}_{\text {medida }}$ & $\boldsymbol{\alpha}_{\text {Ajust }}$ \\
média & média & média & média & média & média & média \\
\hline Telha nova & 76,3 & 76,0 & 70,3 & 70,1 & 72,8 & 70,6 & 72,8 & 70,5 \\
Telha carbonatada & 65,9 & 66,1 & 59,0 & 58,7 & 65,4 & 60,6 & 65,2 & 59,7 \\
Telha com fungos & 88,1 & 88,1 & 84,9 & 84,9 & 76,9 & 78,3 & 84,9 & 82,0 \\
Telha carbonatada/efloresc & 63,9 & 63,9 & 59,2 & 59,0 & 65,4 & 61,4 & 63,8 & 60,2 \\
\hline
\end{tabular}


Figura 10 - Curvas espectrais de absortâncias ajustadas das telhas

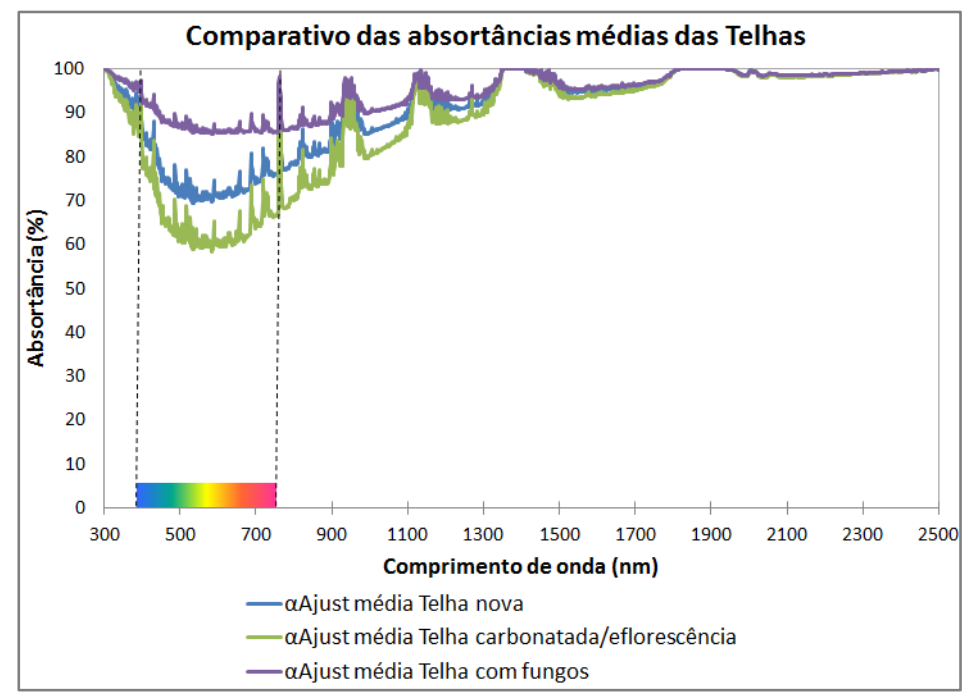

As amostras carbonatadas apresentaram a maior diminuição de absortâncias medidas na faixa de radiação visível do espectro, pois o processo de envelhecimento concomitante de carbonatação e eflorescência modifica características superficiais das amostras, tornando-as mais densas, com acúmulo de sais na superfície, e consequentemente com coloração mais clara, o que impacta diretamente na absortância visível da telha. Por outro lado, os resultados revelaram que aquelas com presença de fungos, devido à irregularidade própria da manifestação biológica sobre elementos construtivos, apresentaram maiores diferenças de absortância solar entre si e entre as faixas do espectro, sobretudo naquela correspondente à radiação do infravermelho. $\mathrm{O}$ escurecimento da telha devido à presença dos fungos alterou significativamente a absortância solar, tornando sua superfície mais absorvedora de radiação solar quando exposta ao sol, o que foi evidenciado nas imagens térmicas das amostras (Figura 6).

Comportamento semelhante foi obtido no estudo realizado por Berdahl et al. (2012), que também observaram o crescimento de fungos $\mathrm{e}$ cianobactérias em telhas, especialmente aquelas que foram expostas às condições do clima quente $\mathrm{e}$ úmido da cidade de Houston. Nesse caso, os autores recomendam que os revestimentos das coberturas de edificações localizadas em clima quente e úmido sejam produzidos com aditivos biocidas, como o óxido de cobre $\left(\mathrm{CuO}_{2}\right)$, a fim de evitar essa alteração ao longo da vida útil da telha, prolongando a absortância solar inicial do revestimento. Portanto, torna-se fundamental o conhecimento do comportamento dos materiais ao longo de sua vida útil, visto que diversos estudos já comprovaram os impactos do envelhecimento natural dos revestimentos sobre suas absortâncias e, consequentemente, sobre o desempenho térmico das coberturas de edifícios.

\section{Conclusão}

Neste estudo foram avaliados os impactos dos processos de envelhecimento natural de telhas de fibrocimento em operação sobre suas absortâncias e seu desempenho térmico. O método, realizado em três etapas, permitiu correlacionar os processos de envelhecimento natural à distribuição da temperatura superficial, a qual indicou que as telhas em estudo sofrem alterações em termos de desempenho térmico.

Os resultados de distribuição das temperaturas superficiais das telhas expostas ao sol apresentaram valores coerentes com as curvas de absortância solar de cada telha. Esses resultados indicaram que, na faixa de radiação do infravermelho, a telha envelhecida há 28 dias e a envelhecida há 36 meses carbonatada apresentaram diferenças menores entre si nos valores de absorção da energia solar do que as diferenças entre a telha envelhecida há 28 dias e a envelhecida há 36 meses com fungos.

Efeitos químico-físicos citados na literatura, tais como diminuição prematura da alcalinidade da matriz cimentícia, densificação da matriz e diminuição da porosidade, na telha carbonatada, podem ser responsáveis pela distribuição da temperatura superficial e da absortância solar do componente envelhecido há 36 meses, o qual apresentou resultados inferiores àqueles de temperatura superficial e absortância da telha nova de 28 dias.

$\mathrm{Na}$ faixa do espectro do infravermelho as diferenças entre os valores de temperatura obtidos 
são menores que aqueles da faixa visível do espectro, como se observa a partir dos termogramas e dos ensaios de absortância. A região do infravermelho é aquela onde se concentra a maior parte da energia responsável pelos ganhos de calor do material. Quando um elemento construtivo absorve aproximadamente toda a radiação solar que sobre ele incide, representa um agente prejudicial ao conforto térmico do usuário, pois essa energia converter-seá em radiação de onda longa, aquecendo os ambientes imediatamente abaixo do elemento construtivo.

Os resultados desta pesquisa indicam o impacto significativo que o envelhecimento natural de telhas de fibrocimento pode exercer sobre o desempenho térmico, visto que a exposição aos agentes atmosféricos e às intempéries altera de forma considerável as características superficiais de tais revestimentos. Essas alterações podem ser tanto pelo processo de carbonatação e eflorescência, bastante comuns em telhas produzidas com materiais cimentícios, como pela proliferação de microorganismos biológicos na superfície. Este estudo, portanto, mostra-se relevante na investigação das propriedades térmicas de componentes construtivos de utilização recentemente normatizada no Brasil, como as telhas de fibrocimento sem amianto, uma vez que, ao longo da fase de operação, podem adquirir características que influenciam sobre seus comportamentos térmicos.

\section{Referências}

AKBARI, H. et al. Aging and Weathering of Cool Roofing Membranes. Report LBNL-58055. Berkeley: Lawrence Berkeley National Laboratory, 2005.

ALMEIDA, A. E. F. S. et al. Carbonatação Acelerada Efetuada nas Primeiras Idades em Compósitos Cimentícios Reforçados Com Polpas Celulósicas. Ambiente Construído, Porto Alegre, v. 10, n. 4, p. 233-246, out./dez. 2010.

AMERICAN SOCIETY FOR TESTING AND MATERIALS. ASTM G173 - 12: standard tables for reference solar spectral irradiances: direct normal and hemispherical on $37^{\circ}$ tilted surface. Pennsylvania, 2012a.

\section{AMERICAN SOCIETY FOR TESTING AND} MATERIALS. ASTM E903 - 12: standard test method for solar absorptance, reflectance and transmittance of materials using integrating spheres. Pennsylvania, 2012b.
ASSOCIAÇÃO BRASILEIRA DAS

INDÚSTRIAS E DISTRIBUIDORES DE

PRODUTOS DE FIBROCIMENTO. O

Fibrocimento e a Construção Sustentável no

Brasil. Revista Green Building, São Paulo, 2014.

Disponível em:

<http://www.abifibro.com.br/?p=894>. Acesso em: 11 nov. 2015.

\section{ASSOCIAÇÃO BRASILEIRA DE NORMAS}

TÉCNICAS. NBR 15220-1: desempenho térmico de edificações - parte 1: definições, símbolos e unidades. Rio de Janeiro, 2005.

\section{ASSOCIAÇÃO BRASILEIRA DE NORMAS TÉCNICAS. NBR 15575: edificações} habitacionais: desempenho. Rio de Janeiro, 2013.

\section{BALTHAZAR, R. D. S. A permanência da}

Autoconstrução: um estudo de sua prática no Município de Vargem Grande Paulista. São Paulo, 2012. Dissertação (Mestrado em Habitat) Faculdade de Arquitetura e Urbanismo, Universidade de São Paulo, São Paulo, 2012.

BERDAHL, P. et al. Weathering of Roofing Materials: an overview. Construction and Building Materials, v. 22, p. 423-433, 2008.

BERDAHL, P. et al. Three-Year Weathering Tests on Asphalt Shingles: solar reflectance. Solar Energy Materials \& Solar Cells, v. 99, p. 277281, 2012.

BOZONNET, E.; DOYA, M.; ALLARD, F. Cool Roofs Impact on Building Thermal Response: a French case study. Energy and Buildings, v. 43, n.11, p. 3006-3012, 2011.

BRÁS, A.; ROCHA, A.; FAUSTINO, P. Integrated Approach for School Buildings Rehabilitation in a Portuguese City and Analysis of Suitable Third Party Financing Solutions in EU. Journal of Building Engineering, v. 3, p. 79-93, 2015.

BRASIL. Lei n 9055, de 1 de junho de 1995, que disciplina a extração, industrialização, utilização, comercialização e transporte do asbesto/amianto e dos produtos que o contenham, bem como das fibras naturais e artificiais, de qualquer origem, utilizadas para o mesmo fim e dá outras providências. Diário Oficial da União, Brasília, 02 de junho de 1995.

BRETZ, S.; AKBARI, H. Long-Term Performance of High-Albedo Roof Coatings. Energy and Buildings, v. 25, p. 159-167, 1997.

BRITISH STANDARD. BS ISO 18434-1: condition monitoring and diagnostics of machines: thermography: part 1: general procedures. London, 2008 . 
BRITO FILHO, J. P.; HENRIQUEZ, J. R.; DUTRA, J. C. C. Effects of Coefficients of Solar Reflectivity and Infrared Emissivity on the Temperature and Heat Flux of Horizontal Flat Roofs of Artificially Conditioned Nonresidential Buildings. Energy and Buildings, v.43, n.2-3, p.440-445, 2011.

CENTRO DE PESQUISAS

METEOROLÓGICAS E CLIMÁTICAS

APLICADAS À AGRICULTURA. Clima de

Campinas. Disponível em:

<http://www.cpa.unicamp.br>. Acesso em: 5 nov. 2015.

CHVATAL, K. M. S.; LABAKI, L. C.; KOWALTOWSKI, D. C. C. K. Estudo do Clima de Campinas: a dificuldade de caracterização e proposição de recomendações de projeto para climas compostos. In: ENCONTRA NACIONAL DE TECNOLOGIA DO AMBIENTE CONSTRUÍDO, 8., Salvador, 2000. Anais... Salvador: ANTAC, 2000.

DIAS, C. M. R. et al. Envelhecimento de Longo Prazo de Telhas Onduladas de Fibrocimento: o efeito da carbonatação, lixiviação e chuva ácida. Cement and Concrete Composites, v. 30, n. 4, p. 255-265, 2008.

DOGGETT, M. S. Degradation of MediumDensity Fiber Cement Siding. The Building Enclosure: strategies for resilient, highperforming buildings. Minnesota, 28 Jan. 2014. Disponível em:

<https://builtenv.wordpress.com/2014/01/28/degra dation-of-medium-density-fiber-cement-siding/> . Acesso em: 17 maio 2016.

DORNELLES, K. A. Absortância Solar de Superfícies Opacas: métodos de determinação e base de dados para tintas látex acrílica e PVA. Campinas, 2008. 160 f. Tese (Doutorado em Engenharia Civil) - Escola de Engenharia, Universidade Estadual de Campinas, Campinas, 2008.

DORNELLES, K. A.; SICHIERI, E. P. Efeitos do Intemperismo Natural Sobre a Refletância de Tintas Brancas Para Coberturas. In: ENCONTRO NACIONAL DE TECNOLOGIA DO AMBIENTE CONSTRUÍDO, 15., Maceió, 2014. Anais... Maceió: ANTAC, 2014.

DOW, C.; GLASSER, F. P. Calcium Carbonate Efflorescence on Portland Cement and Building Materials. Cement and Concrete Research, v. 33, n. 1, p. 147-154, 2003.

EMPRESA DE PESQUISA ENERGÉTICA. Balanço Energético Nacional 2015: ano base 2014. Rio de Janeiro: EPE, 2015.
ETERNIT. Esclarecimentos Sobre as Recentes Reportagens Sobre o Amianto. São Paulo, 29 maio 2012. Disponível em:

<http://www.eternit.com.br/destaques/institucionai s/esclarecimentos-sobre-as-recentesreportagenssobre-o-amianto>. Acesso em: 01 dez. 2015.

FOKAIDES, P. A.; KALOGIROU, S. A. Application of Infrared Thermography for the Determination of the Overall Heat Transfer Coefficient (U-Value ) in Building Envelopes. Applied Energy, v. 88, p. 4358-4365, 2011.

GLASSER, F. P.; MARCHAND, J.; SAMSON, E. Durability of Concrete: degradation phenomena involving detrimental chemical reactions. Cement and Concrete Research, v. 38, n. 2, p. 226-246, 2008.

INSTITUTO NACIONAL DE METROLOGIA, QUALIDADE E TECNOLOGIA. RTQ-R:

regulamento técnico da qualidade para o nível de eficiência energética em edificações residenciais. Rio de Janeiro: INMETRO, 2010.

KALIL, R. M. L. Avaliação Pós-Ocupação e Eficácia Social: estudo de caso comparativo de habitações de interesse social autoconstruídas na modalidade cooperativa autogestionária e na modalidade promoção pública municipal.

Ambiente Construído, Porto Alegre, v. 4, n. 1, p. 37-53, jan./mar. 2004.

KOLOKOTRONI, M.; GOWREESUNKER, B. L.; GIRIDHARAN, R. Cool Roof Technology in London: an experimental and modeling study. Energy and Buildings, v. 67, n. 1, p. 658-667, 2013.

LEVINSON, R.; BERDAHL, P.; AKBARI, H. Solar Spectral Optical Properties of Pigments: part 1: model for deriving scattering and absorption coefficients from transmittance and reflectance measurements. Solar Energy Materials \& Solar Cells, v. 89, p. 319-349, 2005.

LEVINSON, R.; AKBARI, H; REILLY, J. Cooler Tile-Roofed Buildings With Near-InfraredReflective Non-White Coatings. Building and Environment, v. 42, n. 7, p. 2591-2605, 2007.

PAOLINI, R. et al. Effect of Ageing on Solar Spectral Reflectance of Roofing Membranes: natural exposure in Roma and Milano and the impact on the energy needs of commercial buildings. Energy and Buildings, v. 84, p. 333343, 2014.

PAULETTI, C.; POSSAN, E.; DAL MOLIN, D. C. C. Carbonatação Acelerada: estado da arte das pesquisas no Brasil. Ambiente Construído, Porto Alegre, v. 7, n. 4, p. 7-20, out./dez. 2007. 
PIZZOL, V. D. et al. Effect of Accelerated Carbonation on the Microstructure and Physical Properties of Hybrid Fiber-Cement Composites. Minerals Engineering, v. 59, p. 101-106, 2014.

PRADO, R. T. A. P.; FERREIRA, F. L.

Measurement of Albedo and Analysis of Its Influence the Surface Temperature of Building Roof Materials. Energy and Buildings, v. 37, n. 4, p. 295-300, 2005

RILEM Technical Recommendations. CPC-18 Measurement of hardened concrete carbonation depth. Materials and Structures, v. 21, p. 453455, 1988.

ROMEO, C.; ZINZI, M. Impact of a Cool Roof Application on the Energy and Comfort Performance in an Existing Non-Residential Building: a Sicilian case study. Energy and Buildings, v. 67, n. 1, p. 647-657, 2013.

SANTOS, E. I. Comparação de Métodos Para Medição de Absortância Solar em Elementos Opacos. Florianópolis, 2013. Dissertação (Mestrado em Engenharia Civil) - Escola de Engenharia, Universidade Federal de Santa Catarina, Florianópolis, 2013.

SHIRAKAWA, M. A. et al. Fungal and Phototroph Growth on Fiber Cement Roofs and Its Influence on Solar Reflectance in a Tropical Climate. International Biodeterioration Biodegradation, v. 95, p. 1-6, 2014.

SLEIMAN, M. et al. Soiling of Building Envelope Surfaces and Its Effect on Solar Reflectance: part I: analysis of roofing product databases. Solar Energy Materials and Solar Cells, v. 95, n. 12, p. 3385-3399, 2011.
SYNNEFA, A.; SANTAMOURIS, M. Advances on Technical, Policy and Market Aspects of Cool Roof Technology in Europe: The Cool Roofs project. Energy and Buildings, v. 55, n. 1, p. 3541, 2012.

TAHA, H. et al. Residential Cooling Loads and the Urban Heat Island: the effects of albedo. Building and Environment, v. 23, p. 271-283, 1988.

TAILEB, A.; DEKKICHE, H. Infrared Imaging as a Means of Analyzing and Improving Energy Efficiency of Building Envelopes: The case of a LEED Gold Building . Procedia Engineering, v. 118, p. 639-646, 2015.

TANACA, H. K. et al. Discoloration and Fungal Growth on Three Fiber Cement Formulations Exposed in Urban, Rural and Coastal Zones. Building and Environment, v. 46, n. 2, p. 324330, 2011.

TASCA, M. Estudo da Carbonatação Natural de Concretos Com Pozolanas: monitoramento em longo prazo e análise da microestrutura. Santa Maria, 2012. Dissertação (Mestrado em Engenharia Civil) - Escola de Engenharia, Universidade Federal de Santa Maria, Santa Maria, 2012.

UEMOTO, K. L.; SATO, N. M. N.; JOHN, V. M. Estimating Thermal Performance of Cool Colored Paints. Energy and Buildings, v. 42, p. 17-22, 2010.

WERLE, A. P.; LOH, K.; JOHN, V. M. Pintura à Base de Cal Como aLternativa de Revestimento Frio. Ambiente Construído, Porto Alegre, v. 14, n. 3, p. 149-157, jul./set. 2014 .

Thamys da Conceição Costa Coelho

Departamento de Arquitetura e Construção | Universidade Estadual de Campinas | Av. Albert Einstein, 951, Cidade Universitária | Caixa Postal 6021 | Campinas - SP - Brasil | CEP 13083-852 | Tel.: (19) 3521-2306 | E-mail: thamyscoelho@gmail.com

\section{Carlos Eduardo Marmorato Gomes}

Arquitetura e Urbanismo, Faculdade de Engenharia Civil | Universidade Estadual de Campinas | Tel.: (19) 3521-2314 | E-mail: cemgomes@fec.unicamp.br

Kelen Almeida Dornelles

Instituto de Arquitetura e Urbanismo | Universidade de São Paulo | Av. Trabalhador São-Carlense, 400, Parque Arnold Schimidt | São Carlos - SP - Brasil | CEP 13566-590 | Telefone: (16) 3373-9285 | E-mail: kelend@sc.usp.br

\section{Revista Ambiente Construído}

Associação Nacional de Tecnologia do Ambiente Construído

Av. Osvaldo Aranha, $99-3^{\circ}$ andar, Centro

Porto Alegre - RS - Brasil

CEP 90035-190

Telefone: +55 (51) 3308-4084

Fax: +55 (51) 3308-4054

www.seer.ufrgs.br/ambienteconstruido

E-mail: ambienteconstruido@ufrgs.br 